Check for updates

Cite this: RSC Adv., 2017, 7, 43789

Received 16th June 2017

Accepted 31st August 2017

DOI: $10.1039 / \mathrm{c} 7 \mathrm{ra06712g}$

rsc.li/rsc-advances

\title{
Soot oxidation performance with a HZSM-5 supported Ag nanoparticles catalyst and the characterization of Ag species $\uparrow$
}

\author{
Hongcheng Ruan, (D) a Maiko Nishibori, ${ }^{* a}$ Tomoki Uchiyama, ${ }^{\mathrm{b}}$ Kakeru Ninomiya, ${ }^{a}$ \\ Kazutaka Kamitani, ${ }^{c}$ Kazuo Kato, ${ }^{b}$ Yuko Konishi, ${ }^{c}$ Alexander Haensch, ${ }^{d}$ \\ Nicolae Barsan, ${ }^{d}$ Udo Weimar ${ }^{d}$ and Kengo Shimanoe ${ }^{a}$
}

\begin{abstract}
A HZSM-5 supported Ag nanoparticles catalyst, which has a Si/Al ratio of 1500, is synthesized by a simple impregnation method for soot oxidation. Ultrafine Ag nanoparticles (NPs) of 1-2 nm in diameter were well dispersed and stable without any aggregation up to $800^{\circ} \mathrm{C}$, confirmed by high resolution scanning transmission electron microscopy, X-ray photoelectron spectroscopy, and high temperature $\mathrm{X}$-ray diffraction. This catalyst exhibited high intrinsic soot oxidation activity and $T_{\max }$ (peak temperature of DTA curves) values were $362{ }^{\circ} \mathrm{C}$ and $533{ }^{\circ} \mathrm{C}$ under tight contact and loose contact conditions, respectively. Furthermore, the physical and chemical states of $\mathrm{Ag}$ species before and during soot oxidation were examined by in situ X-ray absorption spectroscopy. Two kinds of $\mathrm{Ag}$ species $\left(\mathrm{ZO}^{-} \mathrm{Ag}^{+}\right.$ and Ag NPs) were found in this catalyst; they were reduced and crystallized after heating over $150{ }^{\circ} \mathrm{C}$. The Ag NPs remained stable without any aggregation even after $800^{\circ} \mathrm{C}$, which means the $\mathrm{Ag} / \mathrm{HZSM}-5$ catalyst can be well regenerated after high temperature treatment, ensuring good repeatability of soot oxidation performance.
\end{abstract}

\section{Introduction}

Diesel-engine vehicles are superior to gasoline-engine vehicles in combustion efficiency, fuel economy and emission of $\mathrm{CO}$ and $\mathrm{CO}_{2}$ gases. However, a diesel engine produces more harmful substances of nitrogen oxides $\left(\mathrm{NO}_{x}\right)$ and particulate matter (PM), which mainly consists of soot and a soluble organic fraction (SOF), compared to gasoline-engine vehicles. ${ }^{1-5} \mathrm{PM}$, along with serious environmental and health problems, has been one of the main pollutants in air for the last two decades. Many researchers have focused on the development of aftertreatment systems for PM. A catalyzed diesel particulate filter (C-DPF), which not only traps the PM but also combusts it with a catalyst at low temperatures, is commonly regarded as the most effective technology for reducing PM emission from diesel engines. ${ }^{6-8} \mathrm{PM}$ are directly combusted in the after treatment

${ }^{a}$ Department of Molecular and Material Sciences, Interdisciplinary Graduate School of Engineering Sciences, Kyushu University, Kasuga, Fukuoka, 816-8580, Japan. E-mail: nishibori.maiko.511@m.kyushu-u.ac.jp

${ }^{b}$ Japan Synchrotron Radiation Research Institute, SPring-8, Sayo, Hyogo, 679-5198, Japan

'Institute for Materials Chemistry and Engineering, Kyushu University, Motooka, Nishi-ku, Fukuoka 819-0395, Japan

${ }^{d}$ Institute of Physical Chemistry, University of Tuebingen, Tuebingen D-72076, Germany

$\dagger$ Electronic supplementary information (ESI) available. See DOI: $10.1039 / \mathrm{c} 7 \mathrm{ra06712g}$ system with the presence of oxygen or $\mathrm{NO}_{x}$, achieving the regeneration of the DPF.

Metal-supported catalysts, including $\mathrm{Ag}, \mathrm{Pt}, \mathrm{Pd}$ on $\mathrm{SiO}_{2}$, $\mathrm{Al}_{2} \mathrm{O}_{3}, \mathrm{ZrO}_{2}, \mathrm{CeO}_{2}$ and many others, have been widely investigated for soot oxidation. ${ }^{5,9-18}$ Among the various candidates, $\mathrm{Ag}$ supported catalysts have the explicit advantage in low cost. They have been industrially used in the epoxidation of ethylene and the ox-dehydrogenation of methanol to formaldehyde, ${ }^{19-22}$ the $\mathrm{NO}_{x}$ abatement, ${ }^{23,24}$ the oxidation of ammonia, ${ }^{25}$ methane, ${ }^{26}$ carbon monoxide, ${ }^{27}$ and organic volatile compounds. ${ }^{28}$ For soot combustion, the activity of Ag supported catalysts are found to closely depend on the chemical state, particle size of Ag and their dispersion on support. It has been identified that metallic $\mathrm{Ag}$ is more active in soot oxidation compared to its oxidant. This is because on metallic $\mathrm{Ag}$, the surface oxygen adsorption tends to generate various active oxygen species $\left(\mathrm{O}_{n}{ }^{x-}\right)$ that efficiently promote the soot oxidation reactions. ${ }^{13,15,29}$ However, Ag supported catalysts may suffer degradation issues due to the sintering of metallic Ag at high temperature, where both its chemical states and dispersion may change. ${ }^{30}$

HZSM-5 zeolite is widely used as catalyst or support of catalyst for many chemical reactions, such as cracking of alkane, ${ }^{31-34}$ dehydration of alcohol, ${ }^{35,36}$ disposal of toxic gas ${ }^{37-40}$ and other chemical processes..$^{41}$ This is mainly due to its highly porous structure but excellent thermal stability and mechanical strength. ${ }^{14,42-44}$ Specially, the Bronsted acid sites on its pores are known to accommodate ion exchange for metal supported 
catalysts, yielding strong interactions between $\mathrm{Ag}$ and the acid sites $\left(\mathrm{ZO}^{-} \mathrm{Ag}_{m}{ }^{+}, \mathrm{Z}\right.$ represents $\mathrm{Si}$ or $\left.\mathrm{Al}\right)$. These metallic or ion clusters $\mathrm{ZO}^{-} \mathrm{Ag}_{m}{ }^{+}$, being well known as stable and highlydispersed $\mathrm{Ag}$ species on the support, may anchor each $\mathrm{Ag}_{m}$ particle and prevent their agglomeration. ${ }^{\mathbf{4 5 , 4 6}}$ However, heretofore, there has been no exploration of HZSM-5 supported Ag catalyst for their soot oxidation activity.

In this research, we have investigated the soot oxidation performance with the HZSM-5 supported Ag catalyst. Since the contact points between soot and the catalyst are important for soot oxidation in three-phase boundary, so the well dispersed $\mathrm{Ag}$ is good for soot oxidation. We selected HZSM-5 which has high Si/Al ratio (1500: 1), making it conducive to the formation of metallic Ag on its surface. Moreover, physical and chemical states of $\mathrm{Ag}$ species before and during oxidation were investigated.

\section{Experimental section}

\section{Preparation of HZSM-5 supported Ag catalysts}

H-type ZSM-5 (HZSM-5, Si/Al = 1500, TOSOH Corporation) was selected as catalyst support. Ag catalysts loaded on HZSM-5 (Ag/HZSM-5) were synthesized by an impregnation method illustrated in Fig. 1. In this method, $\mathrm{AgNO}_{3}$ (Kishida Chemical) was simply put into the aqueous solution that contains HZSM-5. The suspended solution was then evaporated under continuous stirring, leaving dark colored precipitates. The residuals were further baked at $350{ }^{\circ} \mathrm{C}$ for $2 \mathrm{~h}$, and calcined at $500{ }^{\circ} \mathrm{C}$ for $5 \mathrm{~h}$ in air. The calcined Ag/HZSM-5 catalyst was used for a series of characterization in this study.

Commercially available carbon black with an average particle size of $5 \mu \mathrm{m}$ (CB, Sigma-Aldrich, Fig. S1a $\dagger$ ) was used to simulate combustion of diesel soot. To evaluate the soot combustion performance at differed contact conditions, mixtures of $\mathrm{CB}$ and Ag/HZSM-5 catalyst were prepared by grinding them in a mortar using pestle or spatula, which are referred as tight contact mixture (M-TC mode) and loose contact one (M-LC mode), respectively.

\section{Material characterization methods}

The morphology of Ag/HZSM-5 catalyst was examined by a scanning electron microscope (SEM, JSM-6340F, JEOL Ltd.), while their microstructures by a $200 \mathrm{kV}$ scanning transmission electron microscopy (STEM, JEM-ARM200F, JEOL Ltd.) and the equipped energy dispersive spectroscopy (EDS). To analyze the chemical states of Ag, X-ray photoelectron spectroscopy (XPS, kratos AXIS Ultra DLD, SHIMAZU Corporation) measurement was also performed using $\mathrm{Al} \mathrm{K} \alpha$ excitation. The crystallinity of the catalyst was evaluated from $50{ }^{\circ} \mathrm{C}$ to $600{ }^{\circ} \mathrm{C}$ with an interval of $50{ }^{\circ} \mathrm{C}$ by the high temperature X-ray diffraction (HT-XRD, Cu$\mathrm{K} \alpha$ radiation, Ultima IV, Rigaku Corporation) in air. The diffraction patterns were recorded from $5^{\circ}$ to $70^{\circ}$ with a step width of $2^{\circ} \min ^{-1}$ and $0.02 \mathrm{~s}$ per step.

Ar adsorption isotherms on HZSM-5 and Ag/HZSM-5 were measured by gas adsorption-desorption analyzer (BELSORPmax, MicrotracBEL Corp.). The materials were pretreated at $350{ }^{\circ} \mathrm{C}$ for $10 \mathrm{~h}$ under vacuum to remove the adsorbed species such as water. Total specific surface area was analyzed by the Brunauer, Emmett, and Teller (BET) method and the pore size distribution was acquired by Saito-Foley (SF) and Barrett-Joyner-Halenda (BJH) method.

The CB oxidation with the Ag/HZSM-5 catalysts were evaluated by a Thermogravimetry-Differential Thermal Analysis system (TG-DTA, STA7300, Hitachi High-Tech Science Corporation) under synthetic air (21 vol\% $\mathrm{O}_{2}$ and 79 vol\% $\mathrm{N}_{2}$, $100 \mathrm{ml} \mathrm{min}{ }^{-1}$ ) using a heating rate of $10{ }^{\circ} \mathrm{C} \mathrm{min}^{-1}$ from 30 to $800{ }^{\circ} \mathrm{C}$. Before the measurement, the catalyst and CB mixtures were preheated at $120^{\circ} \mathrm{C}$ for $1 \mathrm{~h}$ to remove adsorbed water.

The X-ray absorption spectroscopy (XAS) spectra, including $\mathrm{X}$-ray absorption near-edge structure (XANES) and extended $\mathrm{X}$-ray absorption fine structure (EXAFS) of $\mathrm{Ag}-\mathrm{K}$ edge were recorded with BL28B2 at SPring-8, Japan. Dispersive X-ray absorption fine structure (DXAFS) spectra were obtained by a position sensitive detector (CCD, Hamamatsu Photonics K.K., $656(\mathrm{X}) \times 178(\mathrm{Y})$ pixels$)$, using a Si $(422)$ bent crystal polychromator with the laue-configuration. The storage ring was operated with an electron energy of $8 \mathrm{GeV}$ with a current of $100 \mathrm{~mA}$. The sample weight of $150 \mathrm{mg}$ in M-TC or M-LC (95 wt\% $\mathrm{Ag} / \mathrm{HZSM}-5$ and $5 \mathrm{wt} \% \mathrm{CB}$ ) was prepared, and the measurements were carried out at a heating rate of $10{ }^{\circ} \mathrm{C} \mathrm{min}^{-1}$ from room temperature to $800{ }^{\circ} \mathrm{C}$ in the energy range of $25.475 \mathrm{keV}$ to $26.446 \mathrm{keV}$ under flowing synthetic air $\left(21 \mathrm{vol} \% \mathrm{O}_{2}\right.$ and $79 \mathrm{vol} \%$

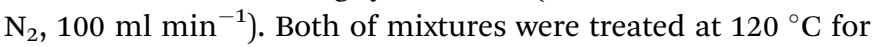
$0.5 \mathrm{~h}$ as a pretreatment. The data were analysed using ATHENA and a suite of IFEFFIT software programs. ${ }^{47,48}$

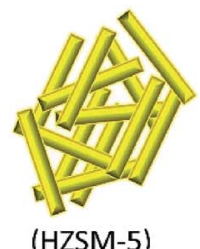

(HZSM-5)
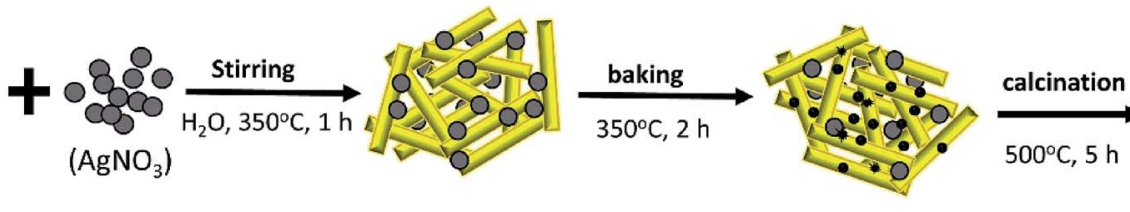

$500^{\circ} \mathrm{C}, 5 \mathrm{~h}$

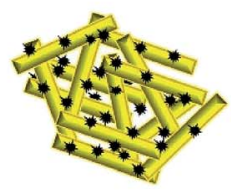

(Ag/HZSM-5)

Fig. 1 Fabrication process of Ag/HZSM-5 catalyst. 


\section{Results and discussion}

\section{Performance on soot oxidation}

Characterization of Ag/HZSM-5 catalyst. Just after the synthesis, the Ag/HZSM-5 catalyst shows no diffraction peaks related to Ag as shown in Fig. 2(a). This suggests the dispersed $\mathrm{Ag}$ is very fine particle which can be assumed as an amorphous metal. However, with increasing the temperature, two peaks appear and become stronger at $38.1^{\circ}$ and $44.3^{\circ}$ from $150{ }^{\circ} \mathrm{C}$, which correspond to the diffraction of (111) and (200) of metallic Ag, as shown in Fig. 2(b). This temperature coincides with the observation by Khan et al., where oxidized Ag starts to dehydrate and crystallize into metallic Ag. ${ }^{49-51}$

Fig. 3(a) shows the SEM image of the as-prepared Ag/HZSM-5 catalyst. It should be noted that the HZSM-5 support maintains its initial structure: rod-like shape with $2-6 \mu \mathrm{m}$ in length. Due to the small size of Ag particles, they are not observed even at high magnification (inset of Fig. 3(a)). On the other hand, STEM image (Fig. 3(b)) clearly shows nano-sized Ag particles are well dispersed on the surfaces of HZSM-5 support. The observed Ag NPs are distributed mostly within 1-2 $\mathrm{nm}$ in diameter, as shown in Fig. 3(c). EDS mapping of the same sample indicates uniform element distribution of $\mathrm{Si}, \mathrm{Al}, \mathrm{Ag}, \mathrm{O}$ and $\mathrm{C}$ in the prepared sample (Fig. S2 $\dagger$ ). Therefore, these well dispersed ultrasmall Ag NPs are supposed to promote soot oxidation by their high activity and the increased contact surfaces with soot particles.

XPS measurement was also conducted to survey the valence states of $\mathrm{Ag}$ in the $\mathrm{Ag} / \mathrm{HZSM}-5$ catalyst (4.5 $\mathrm{wt} \% \mathrm{Ag}$ in this calcined Ag/HZSM-5 catalyst). Fig. 3(d) shows the measured spectra and the fitting results using the respective binding energy of $\mathrm{Ag}$ and $\mathrm{Ag}^{+}$. Though it is not detected in XRD at room temperature (amorphous state), the dominant Ag species on HZSM-5 support are found to be metallic Ag with binding energies of $368.4 \mathrm{eV}\left(\mathrm{Ag} 3 \mathrm{~d}_{5 / 2}\right)$ and $374.5 \mathrm{eV}\left(\mathrm{Ag} 3 \mathrm{~d}_{3 / 2}\right)$. Neighboring peaks appear at $367.8 \mathrm{eV}\left(\mathrm{Ag} 3 \mathrm{~d}_{5 / 2}\right)$ and $373.9 \mathrm{eV}\left(\mathrm{Ag} 3 \mathrm{~d}_{3 /}\right.$ $\left.{ }_{2}\right)^{52,53}$ suggesting the existence of oxidized Ag. The existence of the oxidized Ag can be underestimated by XPS performed in the vacuum environment, which would promote the reduction of the cation Ag.

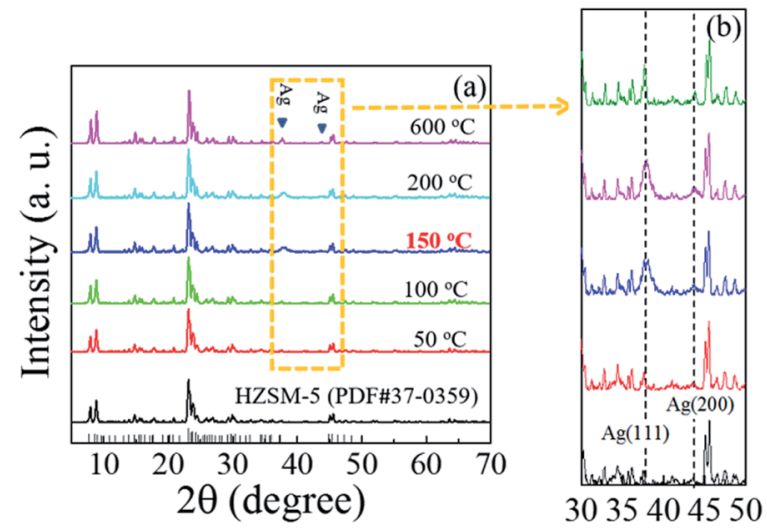

Fig. 2 (a) In situ high temperature XRD patterns of $4.5 \mathrm{wt} \% \mathrm{Ag} / \mathrm{HZSM}$ 5 and (b) enlarge view from $35^{\circ}$ to $50^{\circ}$.
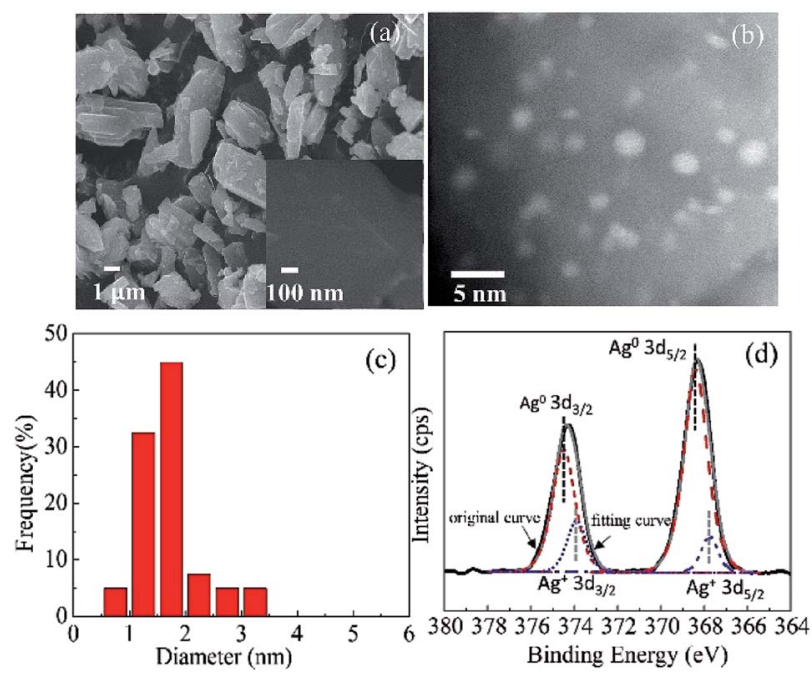

Fig. 3 (a) SEM image, (b) STEM image, (c) Ag particle size distribution, and (d) XPS spectrum for $\mathrm{Ag} 3 \mathrm{~d}$ of $\mathrm{Ag} / \mathrm{HZSM}-5$.

It is well known that silver oxide $\left(\mathrm{Ag}_{2} \mathrm{O}\right)$ decomposes into metallic silver at temperatures above $300{ }^{\circ} \mathrm{C} .{ }^{54}$ In our research, the HT-XRD measurement indicates the oxidized $\mathrm{Ag}$ is reduced to metallic silver at around $150{ }^{\circ} \mathrm{C}$. It is thus suggested that the transformed oxidized $\mathrm{Ag}$ on HZSM-5 is not bulk-like $\mathrm{Ag}_{2} \mathrm{O}$ but other cationic $\mathrm{Ag}$ species. Since $\mathrm{Ag}$ tends to exchange with $\mathrm{H}^{+}$in HZSM-5, it is presumed that Ag cations would preferentially form at the Bronsted acid sites as $\mathrm{ZO}^{-} \mathrm{Ag}^{+}$. However, we used HZSM-5 with high Si/Al ratio of 1500 which contains less ionexchange sites, and it is difficult to form $\mathrm{ZO}^{-} \mathrm{Ag}^{+}$. Therefore, we suggest the formation of some cationic $\mathrm{Ag}$ species by ionexchange with the abundant surface hydroxyl groups (silanols and $\mathrm{H}$-bonded $\mathrm{OH}$ groups) on HZSM-5, as shown in Fig. S4. $\dagger$ It exhibits that DRIFTs spectra of HZSM-5 and Ag/HZSM-5 at room temperature and the infrared parameters of all the hydroxyl groups (Table $\mathrm{S} 1 \dagger$ ).

Table 1 shows the total specific surface area and the pore volume at each pore size evaluated from the Ar adsorption and desorption of HZSM-5 and Ag/HZSM-5. The total specific surface area decreases with the increasing $\mathrm{Ag}$ contents. The pore volume $\left(V_{\mathrm{p}}\right)$ of the pores with $0.39 \mathrm{~nm}$ in diameter which

Table 1 Total specific surface area and pore volume at different pore sizes of $\mathrm{HZSM}-5$ and $\mathrm{Ag} / \mathrm{HZSM}-5$

\begin{tabular}{llllll}
\hline & & & \multicolumn{2}{l}{$V_{\mathrm{p}}\left(\mathrm{cm}^{3} \mathrm{~g}^{-1}\right)^{b}$} \\
\cline { 5 - 6 } Catalyst & $\begin{array}{l}\mathrm{Ag} \\
(\mathrm{wt} \%)\end{array}$ & $\begin{array}{l}S_{\mathrm{BET}}{ }^{b} \\
\left(\mathrm{~m}^{2} \mathrm{~g}^{-1}\right)\end{array}$ & $0.39 \mathrm{~nm}$ & $1.0-1.7 \mathrm{~nm}$ & $1.7-2.0 \mathrm{~nm}$ \\
\hline HZSM-5 & - & 412 & 0.1505 & 0.0085 & 0.0023 \\
Ag/HZSM-5 & 2 & 394 & 0.1434 & 0.0316 & 0.0043 \\
& 4.5 & 377 & 0.1372 & 0.0151 & 0.0149 \\
& 8 & 376 & 0.1372 & 0.0288 & 0.0048 \\
& 12 & 344 & 0.1253 & 0.0118 & 0.0112
\end{tabular}

${ }^{a}$ Specific surface area from BET method. ${ }^{b}$ Total pore volume $\left(d_{\mathrm{a}}=0.4-\right.$ $2.0 \mathrm{~nm}$ ) from SF method. 
derive from HZSM-5 support also decreases with the increasing $\mathrm{Ag}$ contents. Thus, it is thought that some $\mathrm{Ag}$ atoms exist in the pores of HSZM-5. Therefore, it is reasonable to infer that some $\mathrm{Ag}_{m}$ (" $m$ " is the number of $\mathrm{Ag}$ atom) particles (1-2 nm) cover the pores on the surface of HZSM-5, which can stabilize the $\mathrm{Ag}_{m}$ particles on the surface of HZSM-5. On the other hand, $V_{\mathrm{p}}$ of the pores with diameter during 1-1.7 $\mathrm{nm}$ and 1.7-2 $\mathrm{nm}$ increases with the presence of $\mathrm{Ag}$ on the surface of HZSM-5. These pores in the range of 1-2 $\mathrm{nm}$ in diameter are considered to derive from inter-pore between Ag NPs. This result suggests that Ag presents on the surface of HZSM-5, which is consistent with the STEM results above.

Soot oxidation activity. To examine the soot oxidation performance of $\mathrm{Ag}$ loaded on HZSM-5, we compared the $\mathrm{CB}$ catalytic oxidation with Ag-free HZSM-5 and Ag/HZSM-5 for both M-TC and M-LC by TG-DTA measurements in the temperature range from 30 to $800{ }^{\circ} \mathrm{C}$. The soot oxidation activities with $\mathrm{Ag}$ catalysts were investigated by varying the $\mathrm{Ag}$ load from $X=2 \mathrm{wt} \%, 4.5 \mathrm{wt} \%$ and $8 \mathrm{wt} \%$. As shown in Fig. S5, $\dagger$ the 4.5 wt $\%$ Ag/HZSM-5 catalyst shows the lowest $T_{\max }$ (peak temperature of DTA curves, denoted as $T_{\max }$ hereafter) in both TC and LC modes for CB oxidation activity among them, the data were shown in Table S2. $\dagger$ This signifies that $4.5 \mathrm{wt} \% \mathrm{Ag} /$ HZSM-5 catalyst has the highest CB oxidation activity among them.

For the Ag-free HZSM-5 (Fig. 4(a)), the CB oxidation started at around $483{ }^{\circ} \mathrm{C}$ and $499{ }^{\circ} \mathrm{C}$ (ignition temperature, denoted as $T_{\mathrm{ig}}$ hereafter) for M-TC and M-LC, respectively. The maximum heatrelease temperature of $\mathrm{CB}$ oxidation are at 605 and $644{ }^{\circ} \mathrm{C}$ for $\mathrm{M}$ TC and M-LC, respectively. On the other hand, for the $4.5 \mathrm{wt} \% \mathrm{Ag} /$ HZSM-5 (Fig. 4(b)), the $T_{\mathrm{ig}}$ are around $298^{\circ} \mathrm{C}$ and $339^{\circ} \mathrm{C}$ for M-TC and M-LC, and the $T_{\max }$ are around $362^{\circ} \mathrm{C}$ and $533^{\circ} \mathrm{C}$ for M-TC and M-LC, respectively. These results shows that the $T_{\mathrm{ig}}$ of M-TC and M-LC samples with $4.5 \mathrm{wt} \% \mathrm{Ag} / \mathrm{HZSM}-5$ sharply decrease compared to with the Ag-free HZSM-5. In addition, the extracted oxidation temperature is identical to the observation in in situ DRIFT measurement, where maximum $\mathrm{CO}_{2}$ outgas is found at around $351{ }^{\circ} \mathrm{C}$ for TC samples (Fig. S6 $\dagger$ ). The greatly reduced combustion temperature is apparently related to the catalytic effect of $\mathrm{Ag}$ particles. Furthermore, a noticeable exothermal hump peak is found accompanying with a weight loss, starts from around $150{ }^{\circ} \mathrm{C}\left(T_{\mathrm{ig}, \mathrm{h}}\right.$ in Table 2$)$ and reaches to a maximum
Table 2 Total specific surface area and pore volume at different pore sizes of HZSM- 5 and $\mathrm{Ag} / \mathrm{HZSM}-5$

\begin{tabular}{|c|c|c|c|c|c|c|c|c|}
\hline \multirow[b]{3}{*}{ Catalyst } & \multicolumn{8}{|c|}{ CB oxidation performance (oC) ${ }^{a}$} \\
\hline & \multicolumn{4}{|c|}{ M-TC } & \multicolumn{4}{|c|}{ M-LC } \\
\hline & $T_{\mathrm{ig}, \mathrm{h}}$ & $T_{\text {ig }}$ & $T_{\max , \mathrm{h}}$ & $T_{\max }$ & $T_{\mathrm{ig}, \mathrm{h}}$ & $T_{\text {ig }}$ & $T_{\max , \mathrm{h}}$ & $T_{\max }$ \\
\hline HZSM-5 & - & 483 & - & 605 & - & 499 & - & 644 \\
\hline 4.5 wt $\%$ Ag/HZSM-5 & 165 & 298 & 244 & 362 & 155 & 339 & 249 & 533 \\
\hline
\end{tabular}

at around $250{ }^{\circ} \mathrm{C}\left(T_{\max , \mathrm{h}}\right.$ in Table 2$)$ on DTA curves for both of M-TC and M-LC. This is attributed to the reduction of $\mathrm{ZO}^{-} \mathrm{Ag}^{+}$by dehydration and the further crystallization into metallic $\mathrm{Ag}$ nanoparticles considering the observed results in HT-XRD.

The 4.5 wt $\%$ Ag/HZSM-5 catalyst was also evaluated the stability of soot oxidation performance in multiple measurements of CB oxidation activity, as shown in Fig. 5 . The $T_{\max }$ are $388,364,384$ and $392{ }^{\circ} \mathrm{C}$ for the 1st, 2nd, 5th and 10th $\mathrm{CB}$ oxidation cycle test, respectively. There is no obvious difference of oxidation activity during the 10 cycles test. Considering the uncertainty of grinding at each time, it seems that there is

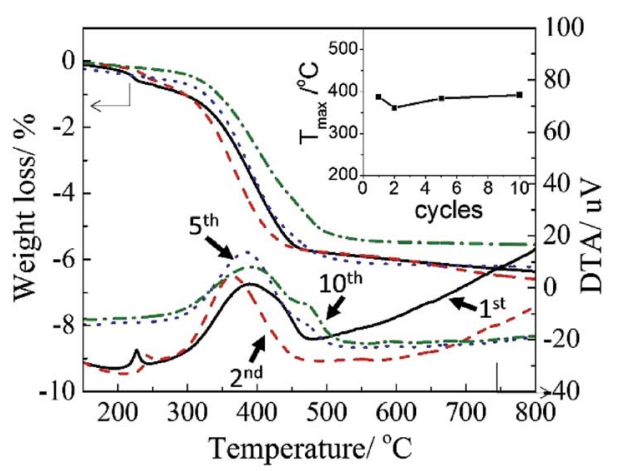

Fig. 5 Repeatability of CB combustion with $4.5 \mathrm{wt} \% \mathrm{Ag} / \mathrm{HZSM}-5$ catalysts in TC mode.

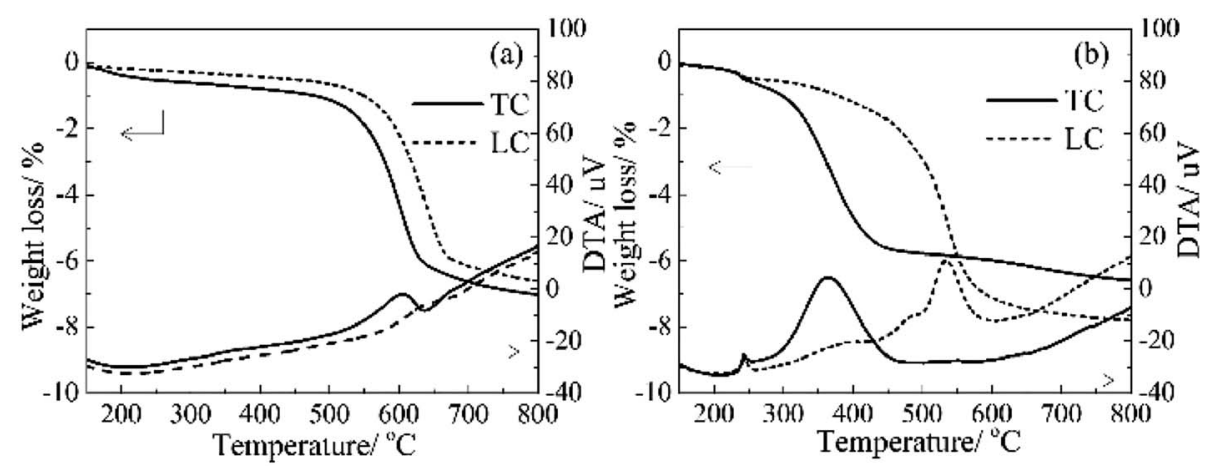

Fig. 4 TG-DTA curves of (a) the soot combustion with HZSM-5 and (b) $4.5 \mathrm{wt} \% \mathrm{Ag} / \mathrm{HZSM}-5$ catalysts. 
almost no significant recession for the CB performance. Furthermore, the STEM observation of the sample after TG-DTA measurement indicates negligible size variation of $\mathrm{Ag}$ particles, as shown in Fig. S7. $\uparrow$ Therefore, the Ag NPs have a high thermal stability, leading to excellent repeatability of soot oxidation performance with Ag/HZSM-5 catalyst.

\section{Characterization of Ag nanoparticles on HZSM-5 support during soot oxidation}

Chemical state of Ag on HZSM-5 support. XAFS spectra of $4.5 \mathrm{wt} \% \mathrm{Ag} / \mathrm{HZSM}-5, \mathrm{M}-\mathrm{TC}$ and M-LC were measured to evaluate the chemical state of Ag on HZSM-5 support and the interaction between Ag species and HZSM-5 support. Fig. 6(a) shows Ag Kedge XANES spectra measured at room temperature. The spectra of $\mathrm{Ag}_{2} \mathrm{O}$ and metal $\mathrm{Ag}$ foil are also indicated as reference. The feature of Ag/HZSM-5 spectrum shows the different behavior from that of $\mathrm{Ag}^{+}$and metallic $\mathrm{Ag}$, but a similar one was observed by Kuroda's group for ion-exchanged Ag/HZSM-5 when being measured at $200-300{ }^{\circ} \mathrm{C} .{ }^{51}$ This spectra suggests that the $\mathrm{Ag}$ species probably compose of $\mathrm{ZO}^{-} \mathrm{Ag}^{+}$and $\mathrm{Ag}$ metal clusters. In $\mathrm{M}$ $\mathrm{TC}$, the XANES spectrum is identical to that of $\mathrm{Ag}$ foil. Remarkably, the chemical state of $\mathrm{Ag}$ species of Ag/HZSM-5 totally changed into metallic Ag just by mixing the catalyst with CB. DRIFTs measurement for CB shows the existence of a lot of transferring hydroxyl groups $(\mathrm{OH})$ groups on the surface of $\mathrm{CB}$ (Fig. S1b $\dagger$ ). Therefore, it is inferred that some oxidized silver are reduced to metallic Ag by the $\mathrm{OH}$ groups on the surface of $\mathrm{CB}$. On the other hand, no obvious change of Ag species can be found in M-LC. This is mainly due to weaker contact condition and less contact points between CB and the catalyst than that of M-TC, which inhibits the transferring of $\mathrm{OH}$ groups from $\mathrm{CB}$ onto the catalyst.

Fig. 6(b) and (c) shows Ag $k^{2}$-weighted EXAFS oscillations of these materials and their Fourier transformation, respectively. Note that the phase shift is not corrected in this paper. Similar to the XANES spectra, Ag/HZSM-5 exhibits different EXAFS
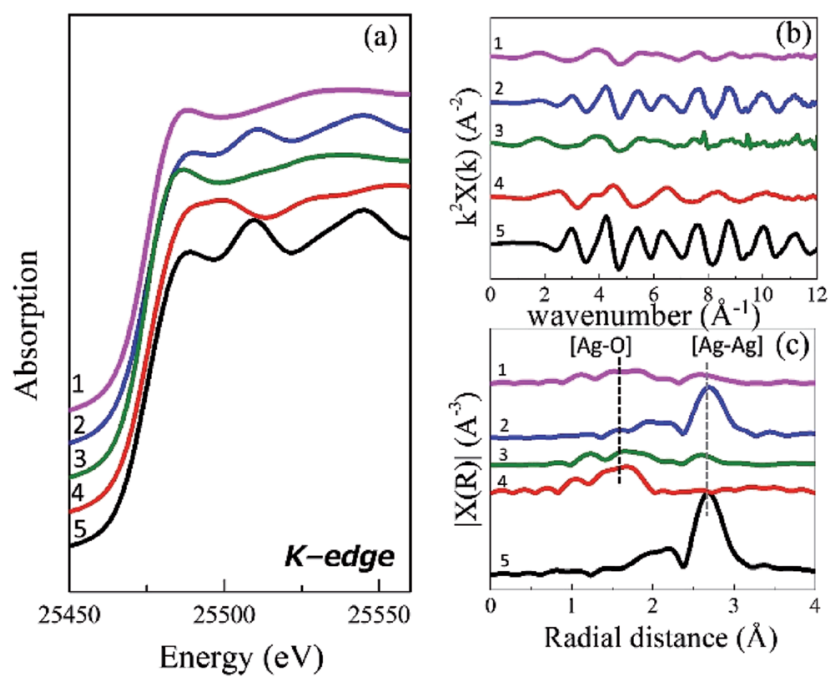

Fig. 6 Ag K-edge absorption spectra, (a) XANES, (b) EXAFS and (c) EXAFS after Fourier transformation for (1) $4.5 \mathrm{wt} \% \mathrm{Ag} / \mathrm{HZSM}-5$, (2) M$\mathrm{TC}$, (3) M-LC, (4) $\mathrm{Ag}_{2} \mathrm{O}$, and (5) Ag foil. oscillation from $\mathrm{Ag}_{2} \mathrm{O}$ and $\mathrm{Ag}$ foil. This indicates that $\mathrm{Ag}$ in $\mathrm{Ag} /$ HZSM-5 has a completely different local structure from these reference materials. M-LC also shows the same oscillation to $\mathrm{Ag} /$ HZSM-5. Two sharp peaks observed in M-LC at $7.8 \AA^{-1}$ and $9.5 \AA^{-1}$ originate from inhomogeneity of $\mathrm{Ag}$ content in the sample, which is inevitable for M-LC due to the insufficient mixing of catalyst with CB. In M-TC, the period of EXAFS oscillation is identical to that of $\mathrm{Ag}$ foil, suggesting that the local structure is metallic Ag as can be expected from the XANES spectrum.

In Fig. 6(c), Fourier-transform EXAFS peaks at $1.69 \AA$ and $2.70 \AA$ correspond to $\mathrm{Ag}-\mathrm{O}$ and $\mathrm{Ag}-\mathrm{Ag}$ bond, respectively. $\mathrm{Ag} /$ HZSM-5 and M-LC show both $\mathrm{Ag}-\mathrm{O}$ and $\mathrm{Ag}-\mathrm{Ag}$ peaks, and the intensity of the $\mathrm{Ag}-\mathrm{Ag}$ peak is weaker than that of $\mathrm{Ag}$ foil. Thus, we confirm again that there is some interaction between Ag nanoparticles and HZSM-5 support. These EXAFS data were investigated with the two-shell model, which composed of Ag$\mathrm{Ag}$ bond and $\mathrm{Ag}-\mathrm{O}$ bond. Table 3 indicates EXAFS curve fitting results of $\mathrm{Ag}$ foil, $\mathrm{Ag}_{2} \mathrm{O}, \mathrm{Ag} / \mathrm{HZSM}-5, \mathrm{M}-\mathrm{TC}$ and M-LC. In Ag/ HZSM-5 and M-LC, the coordination numbers $(N)$ of $\mathrm{Ag}-\mathrm{Ag}$ and $\mathrm{Ag}-\mathrm{O}$ are typical for reported $\mathrm{Ag}$ loaded zeolites. ${ }^{55}$

The smaller value $N$ than $\mathrm{Ag}$ foil $(N=12)$ indicates the formation of $\mathrm{Ag}$ nanoparticles consisting of a small number of $\mathrm{Ag}$ atoms. $\mathrm{Ag}-\mathrm{O}$ in $\mathrm{Ag} / \mathrm{HZSM}-5$ is attributed to the interaction between $\mathrm{Ag}$ species and hydroxyl group $\left(\mathrm{H}_{2} \mathrm{O}, \mathrm{OH}^{-}\right)$adsorbed on the HZSM-5 support. Besides, the distance of $\mathrm{Ag}-\mathrm{O}$ is longer by $0.12 \AA$ than that of $\mathrm{Ag}_{2} \mathrm{O}$. This means that the strength of chemical bond between $\mathrm{Ag}$ and $\mathrm{O}$ is weaker for Ag/HZSM-5 than lattice oxygen. Therefore, oxygen species could be more easily generated from the surface of $\mathrm{Ag}$ particles than lattice oxygen, which is expected to increase the catalytic activity for $\mathrm{CB}$ oxidation. In M-TC, $N$ of $\mathrm{Ag}-\mathrm{Ag}$ (7.0) is still smaller than $\mathrm{Ag}$ foil $(N=12)$, suggesting that small Ag NPs are formed on the catalyst. This is consistent with the result of STEM observation. Since the interaction of $\mathrm{Ag}-\mathrm{O}$ bond cannot be found in $\mathrm{M}-\mathrm{TC}$, the state of $\mathrm{Ag}$ species are metallic one at room temperature after mixing with $\mathrm{CB}$ in TC mode.

\section{Chemical state change of Ag on HZSM-5 support during CB oxidation}

To investigate how the Ag species work for soot oxidation clearly, Fig. 7 shows in situ DXAFS spectra of Ag-K absorption edge of Ag on HZSM-5 support during CB oxidation in M-TC. XANES spectra (Fig. 7(a)) slightly shift to higher energy with temperature and the peak intensities decrease gradually from $25{ }^{\circ} \mathrm{C}$ to $250{ }^{\circ} \mathrm{C}$ at $25.49 \mathrm{keV}$ (Fig. S8a $\dagger$ ), which corresponds to dehydration from the catalyst. However, the major change of the XANES spectra as well as EXAFS (Fig. 7(b) and (c)) cannot be found until $600{ }^{\circ} \mathrm{C}$, since the chemical state of $\mathrm{Ag}$ in M-TC is almost as same as that of metallic Ag. To understand the dynamic structural change of $\mathrm{Ag}$ NPs during CB oxidation, Fourier-transform EXAFS peak intensities of $\mathrm{Ag}-\mathrm{Ag}$ (at 2.70 $\mathrm{\AA}$ ) and $\mathrm{Ag}-\mathrm{O}$ (at $1.60 \AA$ ) are plotted against the reaction temperature in Fig. 8. The exhaust gas (CO and $\mathrm{CO}_{2}$ ) was also monitored by mass spectrometer to check the oxidation of CB (Fig. 9). Generally, Fourier-transform EXAFS peak intensity decreases due to the thermal effect (so called "Debye-Waller effect") without any change of the structure, as 
Table 3 EXAFS fitting refinement results of samples

\begin{tabular}{lllllr}
\hline Sample & Scattering path $^{b}$ & $N^{c}$ & $R^{d} / \AA$ & $S^{2 e} / \AA^{2}$ & $D E_{0}{ }^{f} / \mathrm{eV}$ \\
\hline $\mathrm{Ag}$ foil & $\mathrm{Ag}-\mathrm{Ag}$ & $12^{a}$ & $2.88( \pm 0.00)$ & 0.0095 & 2.6 \\
$\mathrm{Ag}_{2} \mathrm{O}$ & $\mathrm{Ag}-\mathrm{O}$ & $2^{a}$ & $2.07( \pm 0.02)$ & 0.0020 & 8.9 \\
$\mathrm{Ag} / \mathrm{HZSM}-5$ & $\mathrm{Ag}-\mathrm{O}$ & $2.34( \pm 0.43)$ & $2.19( \pm 0.02)$ & 0.0117 & 0.4 \\
& $\mathrm{Ag}-\mathrm{Ag}$ & $1.34( \pm 0.37)$ & $2.87( \pm 0.02)$ & 0.0093 & 1.1 \\
M-TC & $\mathrm{Ag}-\mathrm{Ag}$ & $7.00( \pm 0.64)$ & $2.87( \pm 0.01)$ & 0.0111 & 2.1 \\
M-LC & $\mathrm{Ag}-\mathrm{O}$ & $1.49( \pm 0.36)$ & $2.19( \pm 0.02)$ & 0.0040 & -0.2 \\
& $\mathrm{Ag}-\mathrm{Ag}$ & $1.52( \pm 0.73)$ & $2.86( \pm 0.03)$ & 0.0111 & -1.2
\end{tabular}

${ }^{a}$ Fixed value. ${ }^{b}$ Amplitude reduction factor for all paths are fixed to be the value for $\mathrm{Ag}-\mathrm{Ag}$ single scattering. ${ }^{c}$ Coordination number. ${ }^{d}$ Bond distance. ${ }^{e}$ Debye-Waller factor. ${ }^{f}$ Edge shift $\left(E_{0}=25476 \mathrm{eV}\right) .{ }^{g}$ Residual factor denoted as $100 \times \sqrt{\frac{\sum\left(k^{2} \chi_{\text {obs }}-k^{2} \chi_{\text {calc }}\right)^{2}}{\left(k^{2} \chi_{\text {obs }}\right)^{2}}}$ where $\chi_{\text {obs }}$ and $\chi_{\text {calc }}$ indicates the experimentally measured EXAFS oscillation and theoretically calculated one, respectively.
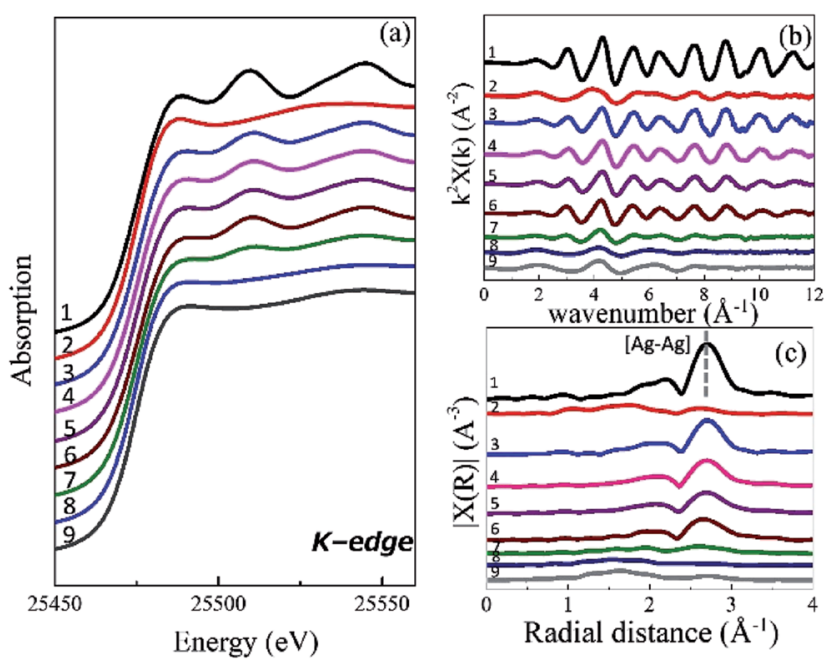

Fig. 7 In situ Ag K-edge absorption spectra, (a) XANES, (b) EXAFS and (c) EXAFS after Fourier transformation for (1) Ag foil, (2) Ag/HZSM-5 and M-TC at: (3) $25^{\circ} \mathrm{C}$, (4) $120^{\circ} \mathrm{C}$, (5) $200{ }^{\circ} \mathrm{C}$, (6) $250{ }^{\circ} \mathrm{C}$, (7) $600{ }^{\circ} \mathrm{C}$, (8) $800{ }^{\circ} \mathrm{C}$ and (9) return to $25^{\circ} \mathrm{C}$.

shown in Fig. 8(c). Fig. 8(d) indicates thermal decomposition of $\mathrm{Ag}_{2} \mathrm{O}$ to $\mathrm{Ag}$ metal, where the formation of $\mathrm{Ag}-\mathrm{Ag}$ and disappearance of $\mathrm{Ag}-\mathrm{O}$ are clearly observed although the thermal effect cannot be ignored. In M-TC (Fig. 8(a)), Ag-Ag shows a decreasing trend due to the thermal effect over the temperature. However, the trend of $\mathrm{Ag}-\mathrm{Ag}$ profile slightly changes from $200{ }^{\circ} \mathrm{C}$ to $480^{\circ} \mathrm{C}$. In this region, the amount of $\mathrm{Ag}-\mathrm{Ag}$ bond is larger than that at other temperatures. $\mathrm{As} \mathrm{Ag}-\mathrm{O}$ bond cannot be found at this temperature range, the intensity increase of $\mathrm{Ag}-\mathrm{Ag}$ bond indicates the crystallization of $\mathrm{Ag}$ nanoparticles at around $220{ }^{\circ} \mathrm{C}$, which is well accorded with exothermal hump peak in TG-DTA. A small amount of $\mathrm{CO}_{2}$ is released at around $220{ }^{\circ} \mathrm{C}$ in Fig. 9(a). We attributes this to the oxidation of a small amount of CB by the crystallization heat. Hence, we conclude that the Ag NPs are the active species for CB oxidation.

In M-LC, the chemical state of $\mathrm{Ag}$ do not change until $200{ }^{\circ} \mathrm{C}$ while the metallic Ag clearly appears over $250{ }^{\circ} \mathrm{C}$, as shown in
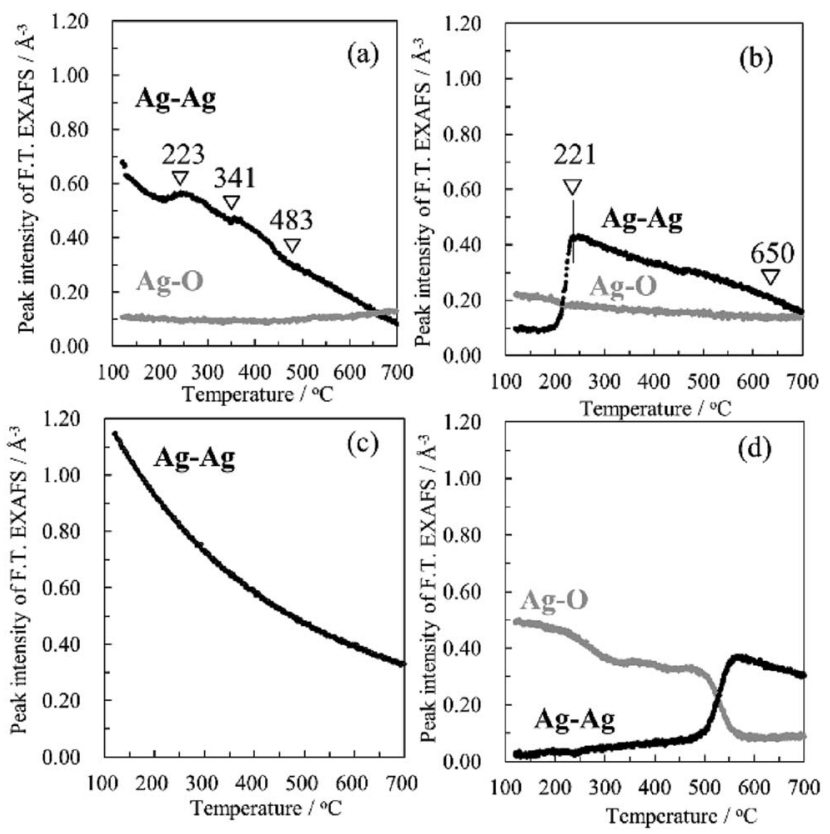

Fig. 8 Peak intensities of $\mathrm{Ag}-\mathrm{Ag}$ and $\mathrm{Ag}-\mathrm{O}$ bond in FT. EXAFS as a function of temperature for (a) M-TC, (b) M-LC, (c) Ag foil and (d) $\mathrm{Ag}_{2} \mathrm{O}$.

Fig. 10. This is due to the reduction of oxidized Ag to metallic Ag accompanying by the dehydration process with increasing temperature, which is also supported by the increasing intensities of peak at around $25.505 \mathrm{keV}$ (Fig. S8b†). Furthermore, in Fig. 8(b), the increase of peak intensity indicates the formation of $\mathrm{Ag}-\mathrm{Ag}$ bond at $221{ }^{\circ} \mathrm{C}$ along with a slight decrease of $\mathrm{Ag}-\mathrm{O}$ bond, which is due to the reduction of oxidized Ag and crystallization of Ag nanoparticles. Identically, some CB oxidation is promoted at this temperature $\left(221^{\circ} \mathrm{C}\right.$, Fig. $\left.9(\mathrm{~b})\right)$. The crystallization temperature $\left(221^{\circ} \mathrm{C}\right)$ coincides with the result of M-TC as well as TG-DTA. After the crystallization, the intensity of Ag-Ag bond decreases due to the thermal effect. These results suggest that Ag metal clusters crystalize and aggregate on HZSM-5 to form small Ag nanoparticles, which work as active sites for catalytic oxidation of CB even in LC mode. 

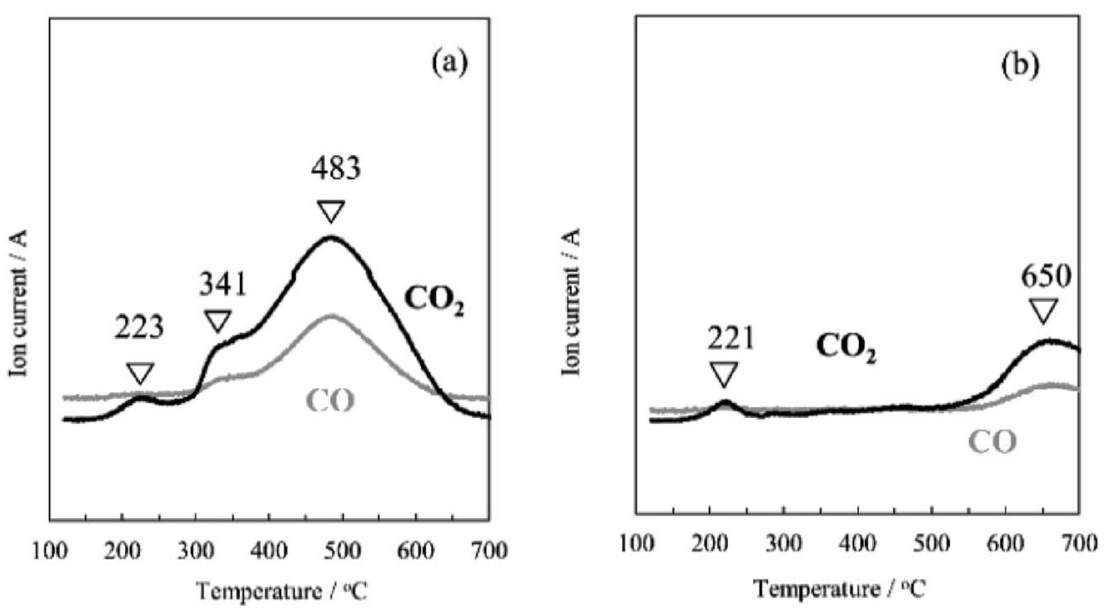

Fig. 9 Exhaust gas analysis $\mathrm{CO}_{x}(x=1$ or 2$)$ are for (a) M-TC and (b) M-LC by mass spectrometer.

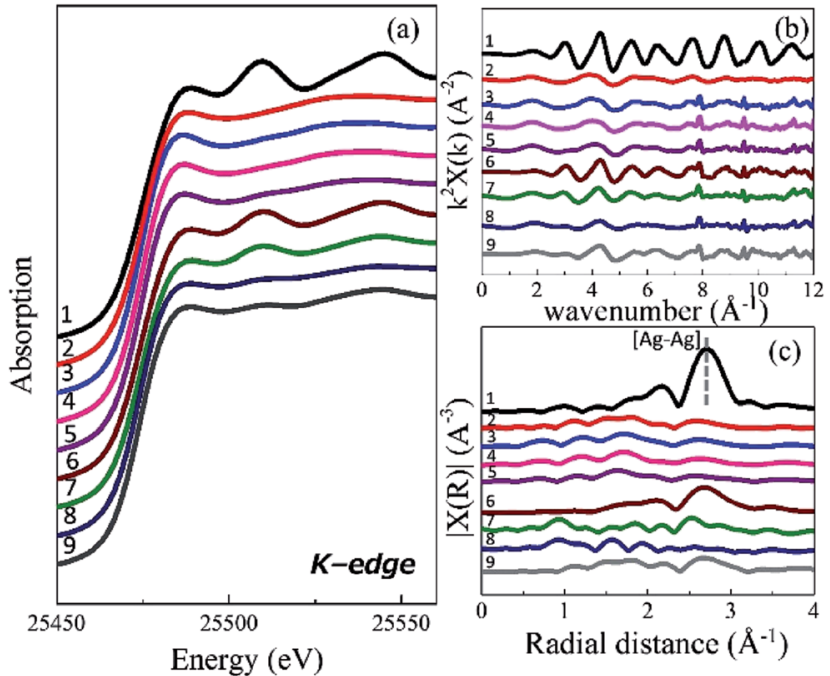

Fig. 10 In situ Ag K-edge absorption (a) XANES, (b) EXAFS and (c) EXAFS after Fourier transformation for (1) Ag foil, (2) Ag/HZSM-5 and M-LC at: (3) $25^{\circ} \mathrm{C}$, (4) $120^{\circ} \mathrm{C}$, (5) $200{ }^{\circ} \mathrm{C}$, (6) $250{ }^{\circ} \mathrm{C}$, (7) $600{ }^{\circ} \mathrm{C}$, (8) $800{ }^{\circ} \mathrm{C}$ and (9) return to $25^{\circ} \mathrm{C}$.

When the temperature is raised from 600 to $800{ }^{\circ} \mathrm{C}$, and then cools down to $25{ }^{\circ} \mathrm{C}$, the oscillation of $\mathrm{Ag}$ spectra in both M-TC and M-LC recover to the original one gradually (curve 3 of Fig. 7 and 10), which signifies the some reduced metallic $\mathrm{Ag}$ become to the oxidized $\mathrm{Ag}$ again. So we suggest that some $\mathrm{Ag}$ NPs $\left(\mathrm{Ag}_{m}\right)$ are melted at this high temperature, and the redispersion of Ag NPs occur at low temperature. Therefore, it suggests that the Ag/HZSM-5 catalyst shows the high stability to the $\mathrm{CB}$ oxidation cycle test. The reasons why the redispersion of Ag NPs can be discussed as follows. The melted $\mathrm{Ag}$ reacts partly with the acid sites $\left(\mathrm{ZO}^{-}\right)$absorbed on the surface of catalyst again at elevated temperature (from $600{ }^{\circ} \mathrm{C}$ ), as shown in earlier study $\mathbf{4 4 , 5 6}^{\mathbf{4}}$

$$
\mathrm{Ag}_{m}+\mathrm{ZO}^{-}+\mathrm{O}_{2} \rightarrow \mathrm{ZO}^{-} \mathrm{Ag}_{m}{ }^{+}+\mathrm{O}^{2-}
$$

Therefore, the $\mathrm{Ag}$ species can return back to the initial state of $\mathrm{ZO}^{-} \mathrm{Ag}_{m}{ }^{+}$(consist of $\mathrm{ZO}^{-} \mathrm{Ag}^{+}$and $\mathrm{Ag}$ NPs) after each high temperature cycle test. This is probably because the $\mathrm{ZO}^{-} \mathrm{Ag}^{+}$ anchors each $\mathrm{Ag}_{m}$ particle and avoids the aggregation of $\mathrm{Ag}_{m}$ particles even after high temperature treatment. Because of this reversible interaction between $\mathrm{Ag}$ nanoparticles with the acid sites (mainly the absorbed hydroxyl group) on the surface of HZSM-5 ( $\mathrm{Si} / \mathrm{Al}=1500)$ support, the Ag NPs can exist stably on the surface of HZSM-5 support without any aggregation even after very high temperature, achieving a good regeneration. This is consistent with the results of the STEM image (Fig. S7 $\dagger$ ). Another possibility is that the pores on the surface of HZSM-5 support behave as a physical anchor to prevent the aggregation of $\mathrm{Ag}_{m}$ particles, this is because the pore size $(\sim 0.5 \mathrm{~nm})$ of HZSM-5 is close to the size of $\mathrm{Ag}_{m}$ particles (1-2 nm), as we discussed above.

\section{Conclusions}

In this study, well dispersed ultrasmall $\mathrm{Ag}$ nanoparticles were prepared on HZSM-5 support by impregnation method and their properties as soot oxidation catalysts were systematically studied. The Ag catalysts are found to exhibit superior catalytic performance with low ignition temperature of as low as $298{ }^{\circ} \mathrm{C}$ in the TC mode. The low ignition temperature is ascribed to the well dispersed silver nanoparticles that increase the physical contact area with soot particles. Using in situ XAS measurements, we are able to unambiguously correlate the soot oxidation activity to the metallic $\mathrm{Ag}$, which are stable from 250 to $600{ }^{\circ} \mathrm{C}$. However, when further increasing the temperature, e.g., at $800{ }^{\circ} \mathrm{C}$, cationic $\mathrm{Ag}$ appears due to the ion exchange interaction with the $\mathrm{OH}$ groups on the surface of HZSM-5. Such interaction increases the high temperature sintering stability of ultrasmall Ag NPs, providing the fabricated Ag/HZSM- 5 catalyst reproducible soot oxidation performance after multiple cycles measurement. Another possibility for explaining the stability of metallic Ag NPs is the physical anchor effect of the pores on the surface of HZSM-5. Given the partial cationic and metallic Ag 
species in the present Ag/HZSM-5 catalyst, they may hold promise in practical diesel exhaust disposing systems where both soot and other gas phase pollutants exist, such as $\mathrm{CO}, \mathrm{NO}_{x}$. The future research will be focused on the supported silver catalyst in various complex environments that matches the application situations.

\section{Conflicts of interest}

There are no conflicts to declare.

\section{Acknowledgements}

We would like to thank Dr C. Lee in STEM observations, Prof. K. Watanabe and Dr K. Suematsu for useful comments and discussions. We also would like to thank for keiji Horio MaicrotracBEL corp. for giving us great suggestions. We acknowledge Late Prof. Y. Teraoka for all of comments and supports. The XAS measurements were performed at BL28B2 of SPring-8 with the approval of the Japan Synchrotron Radiation Research Institute (JASRI) (Proposal No. 2016A1435 and 2016B1302). This work was partially supported by the Photon and Quantum Basic Research Coordinated Development Program from the Ministry of Education, Culture, Sports, Science and Technology, Japan.

\section{Notes and references}

1 L. Pahalagedara, H. Sharma, C. Kuo, S. Dharmarathna, A. Joshi, S. L. Suib and A. B. Mhadeshwar, Energy Fuels, 2012, 26, 6757-6764.

2 H. S. Rosenkranz, Mutat. Res., 1996, 367, 65-72.

3 C. B. Lim, H. Einaga, Y. Sadaoka and Y. Teraoka, Sens. Actuators, B, 2011, 106, 463-470.

4 Y. Teraoka, K. Nakano, S. Kagawa and W. F. Shangguan, Appl. Catal., B, 1995, 5, L181-L185.

5 S. Liu, X. Wu, D. Weng, M. Li and H. Lee, J. Chem. Eng., 2012, 203, 25-35.

6 M. Zheng, G. T. Reader and J. G. Hawley, Energy Convers. Manage., 2004, 45, 883-900.

7 M. M. Maricq, J. Aerosol Sci., 2007, 38, 1079-1118.

8 P. A. Kumar, M. D. Tanwar, S. Bensaid, N. Russo and D. Fino, Chem. Eng. J., 2012, 207-208, 258-266.

9 G. Corro, U. Pal, E. Ayala and E. Vidal, Catal. Today, 2013, 212, 63-69.

10 D. Uner, M. K. Demirkol and B. Dernaika, Appl. Catal., B, 2005, 61, 334-345.

11 Y. Teraoka, K. Nakano and S. Kagawa, Appl. Catal., B, 2001, 34, 73-78.

12 J. Liu, Z. Zhao, C. M. Xu, A. Duan, J. T. Meng and X. J. Bao, Catal. Today, 2007, 119, 267-272.

13 E. Aneggi, J. Llorca, C. D. Leitenburg, G. Dolcetti and A. Trovarelli, Appl. Catal., B, 2009, 91, 489-498.

14 S. Liu, X. D. Wu, D. Weng, M. Li and R. Ran, ACS Catal., 2015, 5, 909-919.

15 K. Yamazaki, T. Kayama, F. Dong and H. Shinjoh, J. Catal., 2011, 282, 289-298.
16 G. Corro, U. Pal, E. Ayala, E. Vidal and E. Guilleminot, Top. Catal., 2013, 56, 467-472.

17 X. T. Lin, S. J. Li, H. He, Z. Wu, J. L. Wu, L. M. Chen, D. Q. Ye and M. L. Fu, Appl. Catal., B, 2017, 217, 530-539.

18 S. Wagloehner, N. N. Maria and S. Kureti, Chem. Eng. J., 2015, 259, 492-504.

19 Y. Shirashi and N. Toshima, J. Mol. Catal. A: Chem., 1999, 141, 187-192.

20 A. N. Pestrvakov, Catal. Today, 1996, 28, 239-244.

21 L. j. Kundakovic and M. Flytzani-Stephanopolus, Appl. Catal., A, 1999, 183, 35-51.

22 A. Nagy and G. Mestl, Appl. Catal., A, 1999, 188, 337-353.

23 P. W. Park and C. L. Boyer, Appl. Catal., B, 2005, 59, 27-34.

24 R. Brosius, K. Arve, M. H. Groothaert and J. A. Martens, J. Catal., 2005, 231, 344-353.

25 L. Gang, B. G. Anderson, J. van Grondelle, R. A. van Santen, W. J. H. van Gennip, J. W. Niemantsverdriet, P. J. Kooyman, A. Knoester and H. H. Brongersma, J. Catal., 2002, 206, 6070.

26 S. Imamura, H. Yamada and K. Utani, Appl. Catal., A, 2000, 192, 221-226.

27 Z. P. Qu, M. J. Cheng, W. X. Huang and X. H. Bao, J. Catal., 2005, 229, 446-458.

28 M. F. Luo, X. X. Yuan and X. M. Zheng, Appl. Catal., A, 1998, 175, 121-129.

29 K. I. Shimizu, H. Kawachi and A. Satsuma, Appl. Catal., B, 2001, 96, 169-175.

30 S. R. Seyedmonir, D. E. Strohmayer, G. J. Guskey, G. L. Geoffroy and M. A. Vannice, J. Catal., 1985, 93, 288-302.

31 K. Kubo, H. Iida, S. Namba and A. Igarashi, Appl. Catal., A, 2015, 489, 272-279.

32 H. Mochizuki, T. Yokoi, H. Imai, R. Watanabe, S. Namba and J. N. Kondo, Microporous Mesoporous Mater., 2011, 145, 165171.

33 H. L. Jin, M. B. Ansari, E. Jeong and S. Park, J. Catal., 2012, 291, 55-62.

34 X. Wang, H. Carabineiro, F. Lemos, M. A. N. D. A. Lemos and F. Ramôa Ribeiro, J. Mol. Catal. A: Chem., 2004, 216, 131-137.

35 V. Vishwanathan, K. W. Jun, J. W. Kim and H. S. Roh, Appl. Catal., A, 2004, 276, 251-255.

36 K. Ramesh, L. M. Hui, Y. F. Han and A. Borgna, Catal. Commun., 2009, 10, 567-571.

37 A. Aranzabal, J. A. González-Marcos, M. Romero-Sáez, J. R. González-Velasco, M. Guillemot and P. Magnoux, Appl. Catal., B, 2009, 88, 533-541.

38 E. Kikuchi, M. Ogura, N. Aratani, Y. Sugiura, S. Hiromoto and K. Yogo, Catal. Today, 1996, 27, 35-40.

39 A. K. Aboul-Gheit and S. M. Aboul-Fotouh, J. Taiwan Inst. Chem. Eng., 2012, 43, 711-717.

40 E. Kolobova, A. Pestryakov, A. Shemeryankina, Y. Kotolevich, O. Martynyuk, H. J. Tiznado Vazquez and N. Bogdanchikova, Fuel, 2014, 138, 65-71.

41 N. Mimura, I. Takahara, M. Inaba, M. Okamoto and K. Murata, Catal. Commun., 2002, 3, 257-262.

42 K. Murata, Y. Y. Liu, M. Inaba and I. Takahara, Energy Fuels, 2010, 24, 2404-2409. 
43 A. A. Gabrienko, S. S. Arzumanov, I. B. Moroz, A. V. Toktarev, W. Wang and A. G. Stepanov, J. Phys. Chem. C, 2013, 117, 7690-7702.

44 B. M. Weckhuysen, D. J. Wang, M. P. Rosynek and J. H. Lunsford, J. Catal., 1998, 175, 347-351.

45 A. Ausavasukhi, S. Suwannaran, J. Limtrakul and T. Sooknoi, Appl. Catal., A, 2008, 345, 89-96.

46 T. Baba, H. Sawada, T. Takahashi and M. Abe, Appl. Catal., A, 2002, 231, 55-63.

47 B. Ravel and M. Newville, J. Synchrotron Radiat., 2005, 12, 537-541.

48 T. Uchiyama, K. Kamitani, K. Kato and M. Nishibori, J. Phys.: Conf. Ser., 2016, 712, 012043.

49 M. A. M. Khan, S. Kumar, M. Ahamed, S. A. Alrokayan and M. S. AlSalhi, Nanoscale Res. Lett., 2011, 6, 434.

50 T. Miyanaga, Y. Suzuki, N. Matsumoto, S. Narita, T. Ainai and H. Hoshino, Microporous Mesoporous Mater., 2013, 168, 213-220.
51 Y. Kuroda, T. Mori, H. Sugiyama, Y. Uozumi, K. Ikeda, A. Itadani and M. Nagao, J. Colloid Interface Sci., 2009, 333, 294-299.

52 X. Yuan, M. I. Setyawati, D. L. Leong and J. P. Xie, Nano Res., 2014, 7, 301-307.

53 E. Kolobova, A. Pestryakov, G. Mamontov, Y. Kotolevich, N. Bogdanchikova, M. Farias, A. Vosmerikov, L. Vosmerikova and V. Cortes Corberan, Fuel, 2017, 188, 121-131.

54 I. Manjubala, M. Sivakumar, T. S. Sampath kumar and K. P. Rao, J. Mater. Sci.: Mater. Med., 2000, 11, 705-709.

55 Y. Suzuki, T. Miyanaga, H. Hoshino, N. Matsumoto and T. Ainai, Phys. Scr., T, 2005, 115, 765-768.

56 T. Morita, Y. Yasuda, E. Ide, Y. Akada and A. Hirose, Mater. Trans., 2008, 49, 2875-2880. 